\title{
LOS TALLERES GENERALES DE MZA (ATOCHA) (1858-1936)
}

\author{
Tomás Martínez Vara \\ Universidad Complutense de Madrid \\ Francisco de los Cobos Arteaga \\ Universidad de Castilla-La Mancha
}

\section{RESUMEN}

El objeto de este trabajo es el estudio del origen, ubicación y evolución de uno de los establecimientos de grandes reparaciones ferroviarias más importantes del país durante la época de las compañías privadas: los Talleres Generales de MZA (Atocha). Se erigieron sobre los terrenos situados a la derecha de la estación de Atocha, cabecera de la doble red, Levante y Zaragoza. El relieve accidentado dificultó la comunicación entre sus diferentes dependencias y, lo que es peor, limitó la expansión que el crecimiento de la red y las nuevas tecnologías exigían, obligando a hacerlo de la única manera posible, esto es, alargando las naves.

Palabras clave: ferrocarriles, tracción a vapor, talleres ferroviarios, talleres generales, tecnología.

\section{ABSTRACT}

The aim of this work is the study of origin, location and evolution of one of the most important railway workshop in the country during the era of private companies: the MZA General Workshop. The were built on the site on the right of Atocha Station, the head of the twin lines to the Levant and Saragossa. The nature of the terrain not only impaired communication between the different premises but also seriously conditioned further building, leaving no option but to build extensions merely by lengthening the existing buildings. This was one of its structural drawbacks.

Key words: railways, steam traction, railway workshops, central workshop, technology. 


\section{Palabras previas}

Estas páginas versan sobre los Talleres Generales ferroviarios, dependientes del servicio de Material y Tracción de la Compañía de los Ferrocarriles de Madrid a Zaragoza y Alicante (MZA), una de las dos grandes del país. Eran las instalaciones donde se realizaban las grandes reparaciones de locomotoras, coches y vagones de la Compañía y el escenario en el que con más propiedad confluían -y entrecruzaban- el mundo industrial y el ferroviario. Por el tamaño de las instalaciones, número de operarios y volumen de actividad se trataba hasta bien entrado el siglo XX de la primera industria de Madrid. El período de análisis comienza mediada la década de los cincuenta del siglo XIX cuando estaban funcionando los talleres de Aranjuez, de los que los Talleres Generales fueron sus herederos inmediatos, y se extiende hasta la década de los treinta del siglo XX.

Como el propio vocablo «taller» ha sido -y es- empleado para referirse a cosas muy diferentes en el campo ferroviario, nos ha parecido oportuno comenzar con un breve apartado (el segundo) aclaratorio para que el lector sepa en todo momento de qué se está realmente hablando. Por sorprendente que pueda parecer, no existe nada escrito sobre el origen, ubicación y desarrollo de las instalaciones de los Talleres. Tampoco lo hay sobre su equipamiento. Ese hueco es lo que pretenden cubrir, aunque sólo sea de forma provisoria, estas páginas. La tarea resultó más laboriosa de lo esperado pues se carece de documentación ad hoc. En su lugar se han utilizado los expedientes del servicio de Vía y Obras de Archivo Histórico Ferroviario (AHF) -el taller de Puentes era el que realizaba muchas de las obras de fábrica e instalaba las máquinas- y la serie Wais, también del AHF, más la información existente para los últimos años en la sección Obras Públicas del Archivo de la Administración (AGA).

\section{Algunas precisiones terminológicas}

Como ya advertimos en otro lugar (Martínez Vara y De los Cobos Arteaga, 2007), en el mundo ferroviario el vocablo «taller» puede inducir a equívocos, pues es utilizado para denominar establecimientos muy diversos, con funciones y tamaño asimismo diferentes. La actividad ferroviaria, por sus propias características, necesita, y así lo hace saber J. L. Lalana (2007), una gran variedad de instalaciones de mantenimiento, con funciones, medios y dotaciones diferentes, a todas las cuales, y con independencia del servicio del que dependan, se las denomina talleres.

Para empezar, dentro de MZA existían los talleres de Pequeño Material, con humildes instalaciones y un número muy reducido de empleados. Dependían del servicio de Explotación o Movimiento y en ellos se construían y reparaban básculas, grúas, cajas de fondos, muebles, lonas y demás pequeños accesorios. La heterogeneidad de objetos fabricados obligaba a subdividir el establecimiento en minúsculas secciones, a las que se las conocía como talleres de básculas, carpintería y tapicería, hojalatería y pintura, y lonas, equipados de medios a tal efecto. Dentro del mismo servicio de Movimiento se encontraban también el taller de Electricidad, donde se construían y reparaban aparatos y accesorios de alumbrado para oficinas, trenes y estaciones, aparatos de calefacción y material eléctrico (carros transbordadores); y el del Telégrafo, anejo, como el de Electricidad, a las Inspecciones de dicho Servicio de Movimiento, que se encargaba de fabricar y reparar aparatos telegráficos y telefónicos y relojes. Con el tiempo el taller Eléctrico se convirtió en servicio autónomo. En los Almacenes Generales y perteneciente al servicio que lleva dicho nombre estaba adscrito un pequeño taller con tres dependencias: litografía, imprenta y foliación. 
Al servicio de Vía y Obras pertenecían los pequeños talleres de la Sección ${ }^{1}$ y el taller de Puentes. Este último se ocupaba de la conservación del material de la vía, construcción de estructuras metálicas de pequeña luz, reparación y refuerzo de puentes, ampliación de estaciones (armaduras, cubiertas y marquesinas), y, en general, de la mejora del material fijo (placas giratorias, carros transbordadores, reparación y construcción de agujas, enclavamientos, accesorios para señales, etc.). El taller de Puentes de MZA, el único hasta ahora estudiado (Martínez Vara y Cobos Arteaga, 2007), fue creado en 1873. Mal ubicado y peor equipado al principio, su actividad fue, como no podía ser de otro modo, escasa. A finales de siglo, sin embargo, el panorama había cambiado profundamente. Para entonces la red se había duplicado, pero, en cambio, el taller apenas había experimentado mejoras ni ampliaciones: sus instalaciones estaban desfasadas, los equipos resultaban obsoletos y el número de trabajadores era reducido. Las futuras instalaciones se situarían, desde 1907, en las del Almacén Central, entre el patio cubierto de éste y los Talleres Generales. El gran salto cualitativo respecto al período anterior fue la utilización generalizada de la electricidad frente al vapor para proporcionar iluminación y mover los equipos, más potentes ${ }^{2}$. La mayor capacidad de trabajo le permitirá al Taller Central proceder al refuerzo y/o sustitución masiva de numerosos tramos metálicos y puentes giratorios, instalación de señales, ampliación de estaciones y muelles, nuevos depósitos de locomotoras y, en general, a la mejora de todo el material fijo. Pero, muy pronto, volvieron los viejos problemas derivados de la escasez de espacio, teniendo los directivos que buscar un nuevo emplazamiento. El lugar elegido -ahora sí resultó un acierto- fue Villaverde Bajo, una pequeña aldea del sur de Madrid, donde permanecerá hasta su conversión en el Taller de Material Fijo de RENFE en 1944³. Inició su andadura en 1924.

El seguimiento habitual -reconocimiento y reparación- del parque de vehículos de motor en las grandes explotaciones se efectuaba en los Depósitos de máquinas ${ }^{4}$ (cada uno tenía asignada una porción concreta de estas) y en las Reservas, y el de material remolcado (coches, furgones y vagones) en los talleres de Recorrido, esparcidos, como los depósitos a los que estaban vinculados, por toda la red según las características de la misma ${ }^{5}$. Unos y otros estaban integrados en la división de Material y Tracción. En algunos casos, Ciudad Real por ejemplo, sus instalaciones y equipos podían alcanzar gran tamaño y realizar operaciones complejas, como la reconstrucción e incluso fabricación de coches y vagones, pero en otros aquellas se reducían a un pequeño taller con una fragua, un cobertizo y algunos trabajadores. Aparte de la limpieza y alimentación de las máquinas, las reparaciones más usuales que se hacían en los depósitos consistían en el examen rutinario y arreglo de las cajas de grasa, recorrido de bielas y émbolos, torneado de ruedas desgastadas, sustitución de tubos, ajuste de cualquier tipo de piezas, y revisión de manómetros, ventiladores, ceniceros, fusibles, areneros y palancas. En los talleres de Recorrido (material remolcado) se hacían reparaciones

\footnotetext{
1 De «escasa importancia», incluidas las secciones de carpintería y cerrajería (MZA, 1908: 11).

2 Una reflexión atinada sobre la introducción de la electricidad y su incidencia espacial en los talleres generales en Lalana y Santos Ganges (2006).

3 Al hacerse cargo RENFE absorbió los talleres de material fijo de Salamanca y Delicias (Oeste), los talleres de enclavamientos de Alcázar de San Juan y Guadalajara (MZA), el equipo de aguas de Madrid-Atocha (MZA) y el almacén de básculas de Madrid-Atocha (MZA).

4 El mantenimiento de las máquinas siempre fue muy exigente, organizándose tradicionalmente en tres tipos: la «diaria» en reservas y depósito, las reparaciones medias como las operaciones de «levante» o de «bajar ruedas» en algunos depósitos y la «gran reparación» de ciclo multianual en los Talleres (Santos y Ganges, 2003 : 116).

5 A nivel de status los «talleres de los depósitos de locomotoras» ocupaban un primer nivel, los «talleres de recorrido» un segundo nivel y los de «material fijo» un tercer nivel.
} 
de forja, suspensión, ruedas, frenado y carpintería (Wais, 1949). Cada taller-depósito tenía su jefe, dependiente del jefe de Tracción, bajo cuyas órdenes están los maquinistas y fogoneros, por un lado, y por el otro los forjadores, torneros, ajustadores, montadores, etc. y personal auxiliar, todos ellos bajo el mando de un contramaestre. A ellos se debían añadir, finalmente, los cargadores de carbón, encendedores, peones y encargados del servicio especial de aguas. A diferencia de los Talleres Generales, el trabajo era en los Depósitos y talleres de Recorrido continuo, debiéndose arreglar las averías urgentes en el momento que se produjeran, día o noche. Por ello estos trabadores eran considerados como personal de la explotación, no siendo obligatorio el descanso dominical. En cualquier caso, el personal ocupado en los depósitos y en estos talleres secundarios superaba, al menos en el caso de MZA, al de los Talleres Generales ${ }^{6}$.

En los Talleres Generales, Centrales o Principales, dependientes del servicio de Material y Tracción, era donde se realizaban las grandes reparaciones, modificaciones y reconstrucciones de material rodante ferroviario (Perdonnet, 1860; Rahola, 1913-1923; Vallespín y Sarabia, 1875; Lalana, 2007). Su existencia en las grandes compañías era inexcusable (Wais, 1949: 161). De ellos, sin embargo, es poco lo que conocemos. Sabemos cómo operaban algunos en Europa, como los de Crewe (Drummond, 1995), Darlington y Swindon (Larkin, 1992) en Inglaterra, Malinas (Van Heesvelde, 2009) en Bélgica o los de Oullins (Chevandrier, 1993) en Francia, por citar algunos ejemplos. Gracias a los recientes estudios, en particular los de J. L. Lalana (2003, 2005, 2007) sobre los de Valladolid (Compañía del Norte), comenzamos a saber cómo funcionaban también en España. Se trataba, en general, de un número variable de naves bien comunicadas entre sí a fin de facilitar la «armonía en la sucesión de trabajos para la rapidez de las grandes reparaciones» (Wais, 1949: 162); de construcción ligera, por si había un cambio de destino (Ruiz, 1895: 429), pero con mucha luz y buena ventilación; estaban ubicados en las líneas principales, en puntos de empalme o en lugares próximos a las grandes estaciones o cabeceras de red y lugares de fácil suministro de materias primas baratas y mano de obra, con grandes posibilidades de expansión en consonancia con el nivel de facturación, mayor tamaño y peso del material móvil y renovada tecnología. Sus grandes secciones (motor y remolcado), y subsecciones (desmontaje y montaje, calderería, ajuste, ruedas, forja y fundición, carpintería, cerrajería, pintura y guarnecido, lonas y toldos, hojalatería y niquelado) recibían, asimismo, el nombre de talleres, dispusieran o no de edificio propio. A diferencia de los depósitos, los Talleres Generales no tenían material específico asignado y el personal descansaba obligatoriamente los domingos.

Las locomotoras que llegaban eran desmontadas completamente, revisándose y «arreglándose todas las piezas de que se componen» (Rahola, 1913-1923: V, 532). Todo este tiempo permanecían, claro es, fuera de servicio ${ }^{7}$. Hasta los años veinte, las compañías españolas se surtieron de locomotoras y, en menor medida, de material remolcado en los mercados del exterior, Europa y EEUU ${ }^{8}$, favorecidas por la libertad de franquicia, lo que permitió a las empresas ferroviarias españolas adquirir material a un precio apto para mantener el negocio ${ }^{9}$. Como en la generalidad de los países, incluido Estados Unidos, el

6 MZA se distribuía en las instalaciones de Pueblo Nuevo (Red Catalana) donde trabajaban, en 1913, 405 agentes, 288 en su depósito y el resto en el taller. Era el que más empleo ocupaba, seguido de Madrid (220 y 178), Ciudad Real (222 y 34), Alcázar de San Juan (192 y 36) y Sevilla (169 y 47). En los diez restantes el volumen de empleo fue inferior. (AHF, W/46/8).

7 Las principales averías de las locomotoras de vapor en Campuzano (1876:53-58).

8 Para la tardía construcción de locomotoras en España ver: Cayón García y Muñoz Rubio (2007: 289). En este trabajo el lector encontrará un buen resumen de la actividad constructora de locomotoras fuera de España.

9 «Sin protección -decía J. Durán y Ventosa (1917)- para las locomotoras grandes y sin mercado para las pequeñas, se explica fácilmente que nadie en época anterior se propusiera implantar en gran escala la industria de construcción de esta clase de máquinas». No es que no haya establecimientos aptos; los hay como es el caso de 
cometido principal de los Talleres Generales fue sólo la conservación y reparación del material rodante (Graves, 1981). Incluso cuando, bien entrado el siglo XX, se inició en España la construcción de locomotoras y remolques, de ella se ocuparon mayormente las empresas especializadas al margen de la explotación ferroviaria (La Maquinista Terrestre y Marítima, Material para Ferrocarriles y Construcciones, Carde y Escoriaza, La Naval, Eugenio Grasset, Construcciones Auxiliares del Ferrocarril, etc. ${ }^{10}$. En los Talleres Generales se fabricó bastante más material remolcado del que se ha pensado, lo que ha llevado a M. Muñoz a afirmar, no sin fundamento, que el sector «gozó de capacidad suficiente para fabricar vehículos ya que contó con medios suficientes para ello» ${ }^{11}$. En todo caso, la excepción fue Gran Bretaña (Drummond, 1989)12 ${ }^{12}$ donde las compañías sí internalizaron desde el principio la construcción (Boughey, 1999), lo que, si hemos de creer a A. Marshall, impidió a la industria ferroviaria británica disfrutar de una hegemonía similar a la de los motores de barco ${ }^{13}$. Sí se fabricaban en España, en cambio, multitud de piezas para equipar a los talleres secundarios de la red, una práctica decisiva en una época en la que aún no existían, o eran escasos, los repuestos estandarizados.

Los Talleres Generales debían ser capaces también no sólo de fabricar cualquier repuesto que se necesitara, sino incluso de diseñarlo o modificarlo para adaptar el material ${ }^{14}$. Sólo se acudía al mercado externo cuando no les era posible fabricarlo en el propio taller. Tiene razón J.L. Lalana (2005) cuando advierte que en lo referente a instalaciones, capital humano y medios de producción, estos talleres no se distinguían en esencia de las fábricas de construcción. La actividad era prácticamente la misma. La diferencia fundamental -y no era pequeña- es que el «taller ferroviario está dirigido por una compañía explotadora, cuya línea de negocio es el transporte y no la construcción». No cabe la menor duda de que, como observa M. Muñoz Rubio, «la capacidad demostrada en el montaje y fabricación de nuevos vehículos (...), la formación de mano de obra cualificada y la transferencia de tecnología a otros sectores» debieron ser elementos fundamentales en el proceso de industrialización del país.

la Maquinista Terrestre y Marítima (MTM), establecimiento al que se refiere J. Durán y Ventosa sin mencionarlo. En él se construyó con éxito un lote de 15 locomotoras que le encargó MZA en 1899; técnicamente -añade J. Durán y Ventosa- resultaron muy buenas, pero desde el punto de vista económico fueron un fiasco al no resultar remuneradoras. Para él la solución pasaba por un incremento de la protección (integral); sólo se alcanzarían precios remuneradores. La discusión sobre el papel de la protección ha sido una constante. Recientemente Cayón García y Muñoz Rubio han terciado en el debate concluyendo: «Ahora bien, sí hubiese sido perfectamente posible poner en marcha un mecanismo de protección, como hicieron otros países, que hubiera permitido a las compañías ferroviarias adquirir los vehículos en casas extranjeras y facilitado madurar a la industria española hasta encontrar una entidad determinada por el propio mercado» (Cayón García y Muñoz Rubio, 2007: 328).

10 De 1920 a 1936 MZA sólo encargarían máquinas de vapor a MTM; la demanda de Norte fue más variada, destacando Babcock and Wilcox y Euskalduna (Cayón García y Muñoz Rubio, 2007: 309).

11 M. Muñoz Rubio: «La aportación española de material ferroviario remolcado: Una primera aproximación». Agradezco al autor su deferencia al permitirme conocer este texto inédito. Basándose en el estudio de los inventarios de las empresas M. Muñoz Rubio estudia la formación de los parques de remolcado y matiza la idea admitida por la comunidad científica de que no hubo efectos de arrastre. En 1902 el parque de material remolcado (sólo vagones) de MZA era de 11.092 unidades, de los que 2.322 (22,04\%) habían sido fabricados en España, y de estos el 94,04\% se hicieron en los talleres de la Compañía, si bien muchas veces no está clara la línea divisoria entre fabricaciones, transformaciones y reconstrucciones. Eso explica que estas cifras no coincidan con las que ofrece el Boletín de la Cámara Oficial de de Industria de la Provincia de Madrid (BCOIPM). Según esta publicación de 1913 en los últimos 20 años se habrían construido 1.822 vagones. De 1915 a 1935 el parque se incrementó en 17.287 vagones, de los que únicamente se habían importado 1.478. Había triunfado la política de corte nacionalista.

12 También en América del Sur por influencia de Gran Bretaña (Guajardo, 2009).

13 Cita tomada de Boughey (1999: 59).

14 Un momento especialmente significativo fueron los años de la Gran Guerra. Como las piezas de repuesto no llegaban, los Talleres Generales se vieron obligados a fabricarlas en buena medida. 
Dependiendo de la magnitud de la red, los grandes talleres daban empleo a centenares o miles de empleados, a los que se les presuponía una buena cualificación, pues muchas de las reparaciones que habían de realizar eran tan complejas que con frecuencia acababan siendo verdaderas reconstrucciones u obras totalmente nuevas. Los Talleres Generales se hallaban bajo las órdenes del ingeniero jefe del Servicio de Material y Tracción, de quien, a su vez, dependían los jefes y subjefes de cada de cada sección. En cada dependencia existía un contramaestre ${ }^{15}$ que era quien se ponía en relación con los listeros ${ }^{16}$ y jefes de equipo y a estos con los operarios, para que se ejecutasen los trabajos Algunos autores, como Rahola (1913-1923: V, 531), creían que los trabajadores de los talleres «producen menos que los de la industria particular» debido al perfeccionismo en las operaciones y porque el sistema $\mathrm{u}$ «organización existente» no premia a los que muestran mayor celo en el trabajo» ${ }^{17}$. Los trabajos efectuados eran más caros, añade Rahola, pero tenían, en cambio, una doble virtud: «garantía de construcción» y ejecución de las reparaciones en la forma y tiempo más conveniente a las necesidades del servicio.

\section{Talleres generales de MZA}

Los Talleres Generales de MZA de Madrid fueron construidos en los años 1856 a 1858, para reemplazar a los muy modestos que en aquel momento había en Aranjuez (locomotoras) y en Madrid (remolcado), adyacente al embarcadero de Atocha, pertenecientes a la antigua Compañía del Ferrocarril Madrid-Aranjuez (1851). El 7 de julio de 1856, su dueño, el banquero y constructor José de Salamanca, traspasó el ferrocarril Madrid-AranjuezAlmansa, y con él sus talleres, al grupo del conde de Morny, B. Chatelus, G. Delahante y conde Le-Hon, todos ellos del Grand Central francés, y a los hermanos Rotchschild. Se obligaba Salamanca a terminar los 80 kilómetros que faltaban por hacer entre Albacete y Almansa. El trato estipulaba, además, que Salamanca transfería a dichos señores el ferrocarril Almansa-Alicante, perteneciente a una sociedad de la que el banquero malagueño era prácticamente dueño absoluto. El ferrocarril Madrid-Alicante en toda su extensión quedó abierto a la explotación en mayo de 1858. Había surgido la primera línea matriz constitutiva de la compañía MZA. La segunda llegaría al otorgarse el ferrocarril Madrid-Zaragoza al grupo mencionado, a los Rotchschild y a la Sociedad Española Mercantil e Industrial (SEMI). El 31 de diciembre de 1856 se había formalizado la escritura de constitución definitiva de la empresa ${ }^{18}$.

De inmediato, este grupo inició un proceso expansivo hacia el centro, sur y este de la Península, adquiriendo líneas nuevas o anexionando otras ya en explotación, con instalaciones propias donde realizar las inexcusables reparaciones del material. La pérdida de autonomía que supuso el cambio de empresa forzó a estos lugares a reconvertir sus instalaciones. En-

15 El contramaestre, generalmente un anterior trabajador especializado, era un mando intermedio. Había uno como mínimo por cada sección; de él dependen los jefes de equipo, listeros, obreros y cuadrillas de peones más los conductores de máquinas fijas. De ahí que debiera conocer muy bien los diversos oficios ejercidos por todo el personal a su cargo y tener suficiente práctica con el fin de aconsejar con sagacidad y exactitud en los trabajos de sus subordinados. Vallée (1958) considera que debía 1) saber las técnicas generales aplicadas en el taller; 2) «asegurar el pleno empleo en tiempo, calidad y cantidad» del personal, materiales y maquinaria; 3 ) hacer de enlace entre los obreros y la Dirección; y 4) mostrar dotes de mando, organizando bien el trabajo.

16 Los alistadores solían proceder de los peones especializados, toman nota de los trabajos ejecutados por los obreros, cursan las peticiones de estos y vigilan su entrada y salida de los talleres.

17 La idea de que la calidad del producto es, en oposición a la industria particular, lo propio de los Talleres Generales es una constante en la literatura del sector.

18 El capital social se fijó en 456 millones de reales, representados por 240 mil acciones de 1900 reales o 500 francos cada una, repartiéndoselas casi por igual el mencionado grupo del Gran Central, de un lado, y los Rothschild y la SEMI, del otro (Tedde, 1978: 2, 20). 
tre 1860 y 1875 construyó y puso en explotación líneas que se le habían concedido como Castillejo a Toledo, Alcázar a Ciudad Real, Albacete a Cartagena y Manzanares a Córdoba. Tras superar la precaria situación financiera, desde 1875, incorporó a su red por absorción y en poco tiempo un segundo grupo de importantes líneas en funcionamiento, parcial o totalmente, como Córdoba a Sevilla (1875), Sevilla a Huelva (1877), Ciudad Real a Badajoz (1880) y Almorchón a Bélmez (1880), Madrid a Ciudad Real (1880), Aljucén a Cáceres (1880), Mérida a Sevilla (1881) y Aranjuez a Cuenca (1883). Con la línea Valladolid a Ariza, abierta a la explotación en 1895, se cerró el ciclo de las grandes construcciones, y con la adquisición en 1899 de la Compañía de los Ferrocarriles de Tarragona a Barcelona y Francia (TBF), con 723 kilómetros, el de las grandes absorciones. En el caso de TBF, MZA no siguió el modelo (francés) aplicado hasta entonces, sino que adoptó el criterio de las compañías americanas de mantener la identidad de la compañía absorbida. TBF llevó balances independientes de MZA (Red Antigua), excepto en el caso del Servicio de Material y Tracción y en la Contabilidad Central. Aún así, los Talleres de Barcelona-Clot, el equivalente a los Talleres Generales de la Red Antigua, siguieron cumpliendo el mismo cometido.

A principios del siglo XX, una vez las absorciones habían llegado a su término, MZA explotaba en 1900 un total de 3.650 kilómetros, de los que 2.927 pertenecían a la llamada Red Antigua y 723 a la Red Catalana. En ese año el número de viajeros sobrepasó los ocho millones y el de mercancías rozó los cinco millones de toneladas, ascendiendo los ingresos de la explotación a la considerable suma de 93.5 millones de pesetas. Un nivel de facturación que requirió de la concurrencia de 397 locomotoras, 1.023 vagones, 340 furgones y 7.904 vagones. La necesidad de atender eficientemente el tráfico en aumento continuo se convirtió en el objetivo primario de la empresa, lo que exigió, claro es, perfeccionar y ampliar el material fijo y rodante, y remodelar y modernizar las instalaciones encargadas de su mantenimiento: los talleres. La absorción de empresas que ya disponían de sus propias dependencias obligó a estos a una continua reestructuración. Únicamente TBF mantuvo -ya se ha dicho- su autonomía. Estaba en lo cierto el BCOIPM cuando en un número especial dedicado a la industria madrileña en 1913 afirmaba que los Talleres Generales de MZA - lo mismo puede decirse del Taller Central de Vía y Obras- siguieron el mismo curso que el aumento del tráfico de la Compañía.

\subsection{Los primeros pasos}

Tres meses después de constituirse la Compañía, mientras se discutía si convenía reunir las estaciones de las líneas de Aragón y del Mediterráneo en una sola cabecera, en Atocha, llega a España el ingeniero francés M. Jullien quien se convertirá en el «factotum» de la Compañía en los primeros momentos ${ }^{19}$. En la sesión del 15 de abril de 1857 expone al Consejo de Administración (CA) la necesidad de crear unos talleres capaces de satisfacer las exigencias crecientes de la Tracción y él mismo se compromete a presentar el dictamen a tal efecto en la siguiente sesión ${ }^{20}$. Aunque la naturaleza del terreno no fuera la mejor por la proliferación de desniveles, M. Jullien creía que, dada la equidistancia entre las líneas de Alicante y Zaragoza, las «inmediaciones de Atocha» eran el punto geográfico más adecuado para colocar los Talleres Generales (Figura 1). Además de estar junto a la estación

19 La llegada de Jullien con amplios poderes, por encima de los de la propia Dirección, para organizar la incipiente compañía e intervenir en todos los asuntos de importancia responde al deseo del Comité de París de confiar su gestión a un ingeniero de «reputación universalmente reconocida». Jullien, desde luego, lo era pues le avalaban el haber ejercido como inspector general de puentes y calzadas, haber sido jefe de la Compañía de Lyon y haber ejercido como ingeniero en la construcción del ferrocarril de Orleáns y en su estación (López García (1986: 68-69).

20 AHF, Actas del CA, lib. 373, fol.52. 
cabecera de la doble red, el emplazamiento reunía otras ventajas como disposición de agua corriente y potable, recursos humanos, fácil acceso a las fuentes energéticas y a las materias primas, que el ingeniero francés no menciona, pero que sin duda conocía bien ${ }^{21}$. Beneficios propios, en definitiva, de las economías de aglomeración, que surgen de la densidad de la actividad económica en los núcleos urbanos. En la sesión del 3 de julio de 1857, el CA da el visto bueno al dictamen, procediéndose de inmediato a la adquisición de los terrenos situados al sureste de la estación y rotonda de máquinas, entre las vías principales de Aragón y Levante al norte y el arroyo Carcabón, que corre en paralelo este-sur por terrenos de arcillas, arenas, margas y arcosas hasta alcanzar la acequia de la Abadía y virar hacia sur en dirección al arroyo del Abroñigal. Preveía una superficie cubierta inicial de 8.680 metros cuadrados, completada con varias dependencias anejas abiertas ${ }^{22}$. La puesta en explotación de la línea de Zaragoza obligaría -creía M. Jullien con razón- a ampliar las instalaciones. No se equivocaba, en octubre de 1858, el Director reconocía ante el CA que las instalaciones ya «resultan insuficientes» ${ }^{23}$.

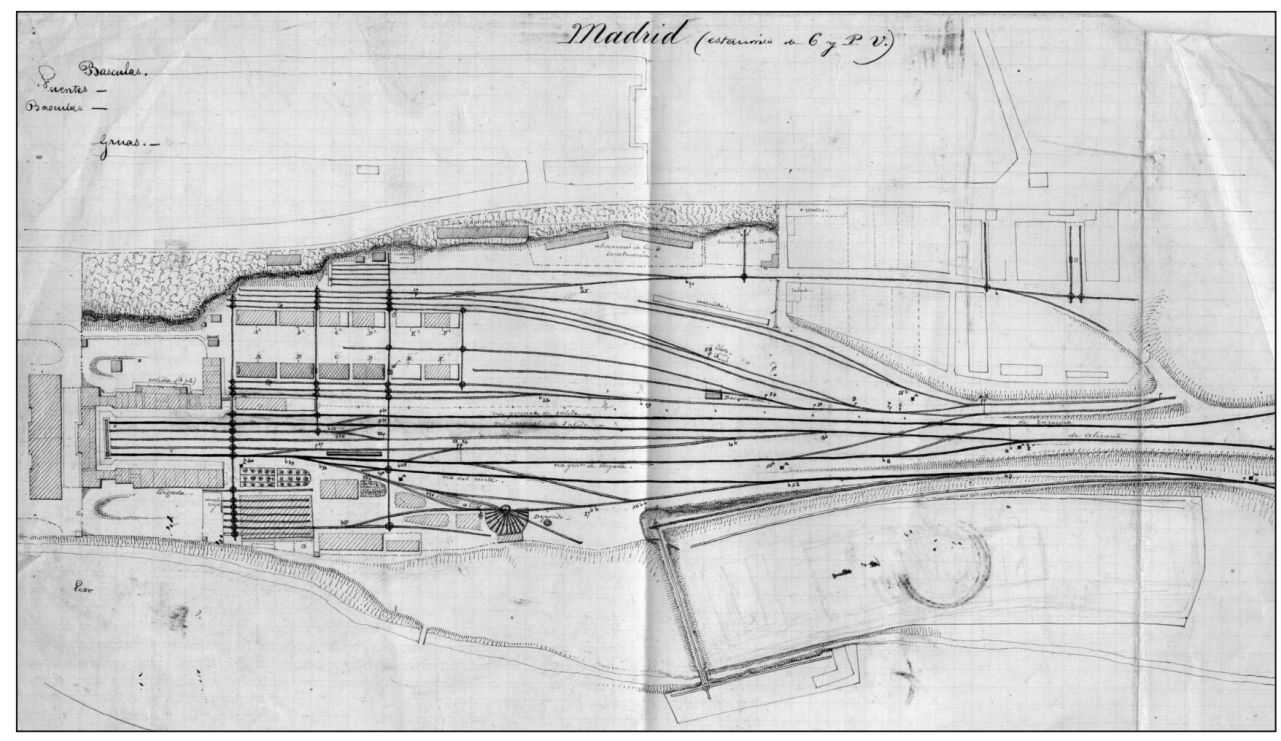

Figura 1. Proyecto de M. Jullien. Al fondo el rectángulo donde irían los Talleres Generales. Fuente: AHF, W/12/4-8.

El recinto tendría forma de rectángulo, dentro del que va a existir una clara especialización zonal; nada resulta aleatorio. Siguiendo las directrices de la época, las instalaciones se articularían en torno a grandes patios internos pues era la forma de obtener la iluminación adecuada hasta la generalización de la electricidad y de poder realizar trabajos externos ${ }^{24}$.

21 Una buena reflexión sobre los criterios seguidos por las compañías a la hora de elegir emplazamiento en V. Ruiz (1895: 429).

22 AHF, W/12/5-4.

23 AHF, CA, Actas, lib. 373, fol. 338.

24 AHF, W/11/8. 
Adyacente a la estación (Figura 2), aunque separada de ella por un terraplén de más once metros, al nivel natural, se situaría el almacén general -central logística de la Compañía y depósito principal de los materiales que debían surtir a las dependencias de la red $^{25}-$, seguido del taller de máquinas con sus auxiliares: calderería, $1.400 \mathrm{~m}^{2}(70$ x 20), vástago originario de donde sale el resto de las naves a modo de dientes de sierra, perfectamente comunicadas entre sí; montaje con sus fosos, $1.980 \mathrm{~m}^{2}$ (66 x 33), es el que en realidad articula el conjunto de las instalaciones y conecta directamente con el exterior (Lalana, 2005: 56), y ajuste, $1.380 \mathrm{~m}^{2}$ (46 x 30), de donde salían las piezas ya elaboradas, ambos con columnas de hierro fundido, siguiendo las normas de la época, con soportes de una sola pieza para sustentar directamente las transmisiones principales; forja $1.320 \mathrm{~m}^{2}$ (66 x 20), unido al de fundición (hierro y cobre), $800 \mathrm{~m}^{2}$ (40 x 20). A diferencia de los dos primeros, en los otros no se trabajaba exclusivamente para la sección sino que suministraban piezas a toda la compañía y eran utilizadas también por la sección de remolcado. El depósito de ruedas se situó, obviamente, contiguo al taller de ajuste y tornos, mientras el de maquinaria fija (máquinas-herramienta) se acomodó en el patio entre el de ajuste y el de fundición, junto a la chimenea. En dependencias anejas, junto al mencionado arroyo, se ubicaron el almacén de modelos y el laboratorio químico. La existencia de terraplenes, la disposición de las vías principales al norte y la presencia del arroyo Cartabón, o de las yeserías, al sur, que obligará a levantar sólidos muros de contención ${ }^{26}$, explican la orientación dada a estas instalaciones. Evolucionaron -luego se verá- de la única manera que podían hacerlo, esto es, prolongando las naves (dientes) existentes.

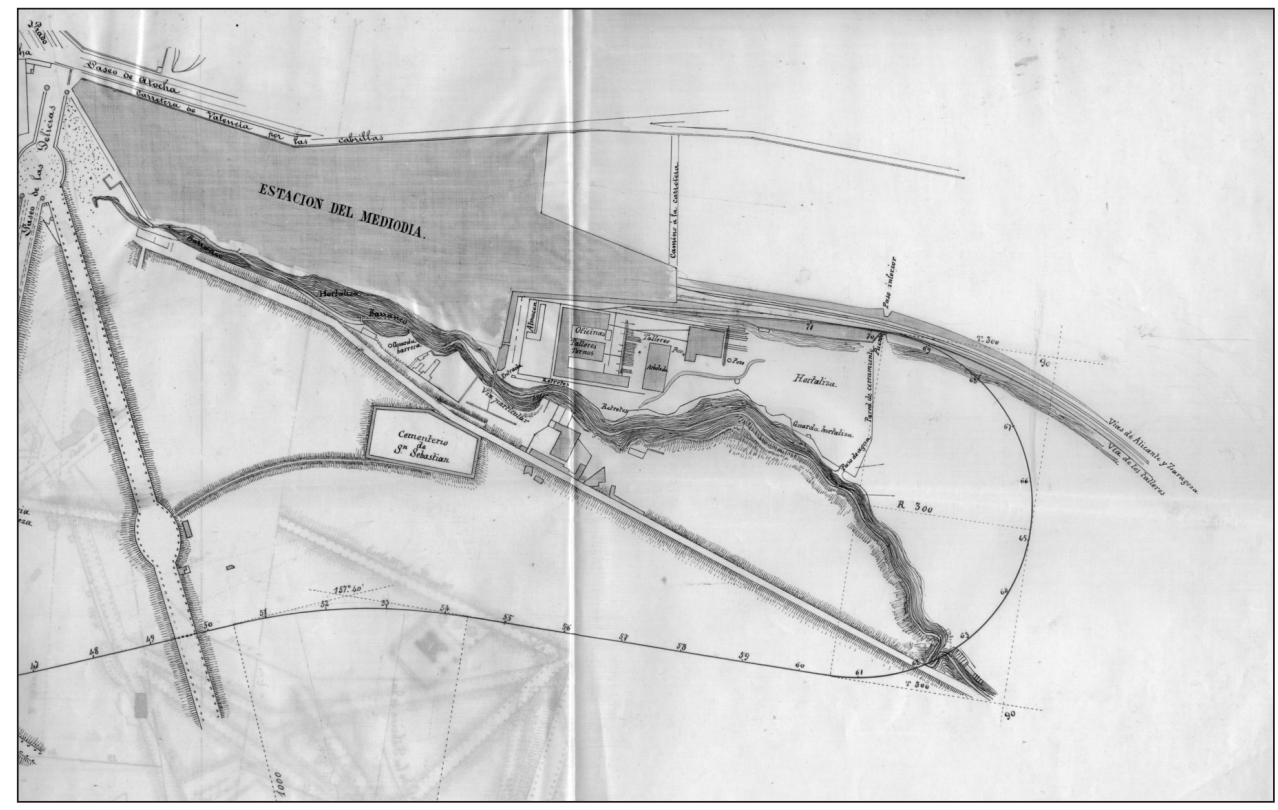

Figura 2. Plano de Talleres Generales en 1861.

Fuente: AHF, W/18/4: Ferrocarril del Contorno.

25 Allí se reciben los artículos y desde allí se remiten a los almacenes auxiliares, esparcidos por las líneas.

26 Ver AHF, M73/4; M/2/39; C/302/2; C/646/1-4; C/76/1-1. 
A continuación, perpendicular a las vías y al arroyo Carcabón, en un edificio diferente, se colocó el taller de carrocería, $1.800 \mathrm{~m}^{2}$ (30 x 60), también con sus respectivas dependencias (carpintería, pintado de carruajes y guarnicionería) y flanqueado al oeste por el depósito de aguas, el almacén y el horno de secar maderas y el depósito de vehículos ya montados, al sur por el taller de lavado y al este por el almacén de maderas. Con el tiempo se creó al oeste una nueva nave, donde se ubicaron los talleres de sierras, cerrajería, y guarnecido y se alargó el almacén de maderas creándose el taller de reparación de coches con bogies ${ }^{27}$.

Dentro y fuera del recinto, la manutención y el movimiento entre las dependencias se realizaría por las playas de vías ortogonales, pequeñas placas giratorias, cangrejos y carros transbordadores perpendiculares a las vías, caballetes de levante, grúas-pórtico, puentes grúa y grúas móviles ${ }^{28}$. Un relieve tan accidentado por los cuatro lados dificultó la comunicación de los Talleres con las vías principales, especialmente los de material remolcado. El acceso a las instalaciones -necesariamente por la vía del ferrocarril de contorno que relacionaba la estación de Norte con Atocha y mediante retroceso, obligaba a realizar numerosas e intricadas maniobras. El tener que utilizar la vía del contorno acarreaba no pocos problemas ${ }^{29}$. La estación y los talleres se comunicaban por medio de dos rampas; los obreros accedían por el camino de las yeserías, sin necesidad de atravesar la estación ${ }^{30}$.

El presupuesto de las obras ascendía a 360.000 francos, a los que se debía añadir la parte alícuota de los 400.000 que suponía nivelar el piso de la estación y el taller (120.000 metros cúbicos). La suma sólo era -y así lo hace saber M. Jullien- una aproximación. En cualquier caso, como en todo el conjunto de la estación, las instalaciones del taller deberían ser simples, aunque amplias, bien aireadas e iluminadas y susceptibles de ampliación, y, sobre todo, económicas, con armaduras, materiales y cubierta al uso del país. La única novedad sería el empleo de columnas de fundición en lugar de las de madera para sostener las techumbres y evitar incendios ${ }^{31}$. Obviamente la construcción de fosos y la necesidad de colocar tirantes muy fuertes para instalar las transmisiones de las máquinas-herramientas y los carretones-grúa en los talleres de montaje y ajuste supusieron un plus en el gasto. Pide Jullien que de inmediato se proceda a equipar del instrumental adecuado: cubilotes, martillos-pilón (accionados mediante vapor), grúas hidráulicas, máquina de vapor para mover las demás máquinas-herramientas: tornos, taladros, cepilladoras, cizalladoras, esmeliradoras/afiladoras, mandrinadoras, rectificadoras, fresadoras, etc. $)^{32}$, y aconseja que se contraten como instructores técnicos del exterior, preferentemente franceses ${ }^{33}$. El 14 de junio de 1858, a propuesta de Chatelus, es nombrado ingeniero Jefe de los Talleres el ingeniero civil francés Albaret, quien habrá de ocuparse también de su construcción ${ }^{34}$; el taller de reparación de máquinas comenzará a funcionar desde febrero de de $1859^{35}$. El

27 Chasis rectangular dotado de dos o tres ejes y unido a la caja del vehículo ferroviario mediante un pivote vertical u otro sistema de articulación real o virtual. Se utiliza para facilitar y mejorar el movimiento de los vehículos en las curvas.

28 Para el servicio de carros los talleres se comunican con el exterior por la entrada reservada a los almacenes. Los empleados de la Compañía podrán comunicarse con los Talleres desde cualquier punto de la estación por medio de alguna de las escaleras. (Revista Peninsular Ultramarina, 16, de noviembre de 1857).

29 AHF, W/12/1-6.

30 Memoria presentada por el CA a la Junta General de Accionistas el 31 de mayo de 1858, reproducida GCH, el 13 junio de 1858 .

31 Ver los mapas de 1861 (AHF, W/18/4-2) y 1870 (AHF, W/11/8).

32 Lalana (2005).

33 A principios de 1858 los Talleres Generales de Madrid ocupan ya más personal que los de Aranjuez (AHF, Actas CA, lib. 373, fols. 236-240). Los puestos de responsabilidad son ocupados por franceses.

34 AHF, Actas CA, lib. 373, fols. 285-6.

35 Memoria presentada por el CA a la Junta General de Accionistas el día 20 de mayo de 1859, reproducida en la GCH de 3 de julio de ese año. Los nuevos talleres de máquinas y vagones presentan una superficie 
27 de abril de ese año el Director, ufano, informa al CA del primer vagón construido ${ }^{36}$. Ese mismo año es aprobado el Reglamento -muy elemental aún- de Contabilidad de los Talleres Generales que regirá en lo sucesivo [Orden de Servicio n ${ }^{\circ} 9$ (MZA, 1862: 59-65)] hasta el establecimiento del Reglamento Provisional para la Contabilidad en 1908 (MZA, 1908). Sobre este documento se volverá más tarde.

\subsection{Una expansión tan necesaria como difícil e incompleta}

Establecidas las bases, la estructura de los Talleres Generales apenas cambió en el futuro. Si en los primeros tiempos priman las obras de acondicionamiento de las distintas secciones, desde finales del siglo, aprovechando la buena coyuntura del negocio ferroviario (aumento extraordinario del tráfico), se realizan las primeras reformas y ampliaciones importantes como respuesta al incremento del parque de vehículos debido a la expansión de la red y a los requerimientos exigidos por los continuos adelantos técnicos, aunque, eso sí, sin salirse aún de la propia tecnología del vapor. A finales del siglo quedaban muy lejos las 142 locomotoras, 242 furgones y 1320 vagones de los primeros años. En 1892 el parque de vehículos ascendía ya a 389 locomotoras, 936 coches, 335 furgones y 7423 vagones ${ }^{37}$. Cuando estalla la Gran Guerra, 1914, los guarismos se han doblado (862 locomotoras, 1716 coches, 669 furgones y 17932 vagones). El crecimiento cuantitativo es importante, pero también lo son los cambios cualitativos. Desde 1901, las locomotoras de dos y tres ejes -es decir, las de menor potencia y mayor antigüedad- pierden en favor de las más modernas y pesadas de cuatro ejes y compound (Cayón García y Muñoz Rubio, 2007), lo que no deja de ser, claro es, un indicio de renovación tecnológica. Pero, no sólo hubo mejoras en el diseño de las locomotoras, sino también, y con carácter acumulativo, en el de los vagones de carga, cuya capacidad aumentó (de 10 a 15 y 20 toneladas), al ser dotados de nuevos ejes y cajas con bordes metálicos, sin que ello provocase un notable incremento del peso muerto ${ }^{38}$.

Durante estos años se produjeron, asimismo, otros varios avances de carácter técnico relevantes en el utillaje de los talleres como la soldadura, el uso de herramientas pequeñas movidas por aire comprimido, o las máquinas herramientas de mayor tamaño, aunque más decisivo fue la introducción de la electricidad como fuente energética (Caron, 2003). Con ella, las plantas industriales ganaron en seguridad, el proceso de producción se hizo continuado (se podía trabajar día y noche ininterrumpidamente) y también fue más eficiente. Para los grandes talleres en general ello significó un gran salto hacia adelante ya que, además de proporcionar iluminación (la luz natural dejó de ser un hecho decisivo), con los nuevos puentes grúas eléctricos, que requerían edificios muy espaciosos con cimientos sólidos, se podrán levantar locomotoras enteras y con los motores eléctricos de funcionamiento autónomo se incrementarán los rendimientos, al permitir adaptar el ritmo de cada uno a la máquina donde se acople (cada máquina podía disponer de su propio accionamiento). Su difusión desde finales del siglo XIX -«la década 1899 a 1909 fue el punto de viraje de la electrificación de la industria» (Sharling, 1981: 641-642)- representó un paso decisivo

cubierta de 11.150 metros (2.470 más de la prevista por M. Jullien), «provista de las herramientas y máquinas necesarias»; «sólo falta, y esperamos que en breve», una cierta cantidad de tornos, grúas y carros, que formarán a buen seguro en conjunto «la más hermosa fábrica en explotación que hay en España», un conjunto «digno de la capital de la monarquía española» (GCH, 5 de junio de 1859).

36 Según la Revista de Obras Públicas (ROP) en su núm. 18, pág. 220, de 1858, los Talleres de MZA de Madrid habrían construido en ese año 10 vagones de bordes altos, diseñados por el ingeniero español E. Page.

37 Ver la web de la FFE http://www.docutren.com/archivos/estad/mza00.htm

38 Sobre la capacidad creciente de los vagones de mercancías» ver ROP, 1905, n. 53, pp. 196 y 204. 
en la sustitución del vapor en la manufactura; la maquinaria se mueve por fuerza motriz independiente para cada aparato, sin necesidad de las transmisiones complicadas de los antiguos talleres (Landes, 1979: 311). Con el tiempo desaparecerá la voluminosa máquina central o motor único de vapor (la máquina de movimiento), que atendía las necesidades energéticas de todo un edificio, con la energía distribuida a través de un conjunto muy complejo de innumerables ejes, ruedas, poleas y correas de transmisión que movían todas y cada de una de las máquinas. Mas, si el uso de la electricidad para la luz artificial se extendió con prontitud en España ${ }^{39}$, el consumo de fuerza en la industria era a principios de siglo todavía muy limitado ${ }^{40}$, incluida la capital Madrid (Aubanell, 2004) ${ }^{41}$. Tampoco en los talleres ferroviarios, la introducción de la electricidad como fuerza motriz independiente tuvo nada de precoz. Como han escrito J.L. Lalana y L. Ganges (2006) a propósito de este asunto, antes de su plena adopción se dieron fases intermedias marcadas por la instalación de generadores eléctricos asociados a las máquinas de vapor o el uso de las viejas máquinas herramientas que tuvieron sus calderas de vapor reemplazadas por motores eléctricos, pero su transmisión mecánica conservada.

Todos estos fenómenos tenían que afectar necesariamente a los Talleres Generales de Madrid de MZA. En el año 1890 se puso el alumbrado, haciéndose una instalación para el taller de máquinas y otra para el de coches: el consumo de vapor resultaba elevadísimo. La fuerza motriz se instaló en 1903 y consistió en 4 motores de 50 HP y uno de $90^{42}$. Los gestores se vieron en la necesidad de ampliar el recinto ${ }^{43}$, tarea harto difícil por lo ya expresado, alargar las naves -eso es lo que se hace- y reestructurar algunas dependencias para así ganar el espacio que las nuevas circunstancias demandaban. De este modo, en 1891 el subdirector remitía un oficio al ingeniero Jefe de Vía y Obras -de él dependía el Taller de Puentes que es quien realizaría la mayoría de las obras- en el que le exponía «la necesidad de continuar el terraplén donde se hallan situados los edificios de los Talleres a fin de construir el anejo al de carruajes y de que haya espacio suficiente junto al horno de secar maderas [situado junto al arroyo Carcabón] para las maniobras necesarias ${ }^{44}$. Entre 1897 y 1913 se proyectan -y realizan-, entre otras, las siguientes obras: alargamiento de algunos fosos del taller de montaje para facilitar la reparación de las máquinas de ocho ruedas $^{45}$, ampliación de los talleres de tornos, quedando reducido el parque de ruedas a la mitad de su extensión ${ }^{46}$, forja y fundición, a los que alargará en dirección este y donde se instala en 1906 una grúa-puente eléctrica, y en el de carpintería ${ }^{47}$; reparación y prolongación

39 Comenzó cuando, en el año 1875, los Srs. Dalmau instalaron en Barcelona una máquina Gramme para alumbrar los talleres de la MTM. A partir de entonces, numerosas centrales proliferaron a lo largo y ancho del país. A principios del siglo XX la iluminación eléctrica se había extendido a las ciudades más importantes.

40 Aunque todavía en 1916 Pérez del Pulgar, profesor de Electrotecnia del ICAI, declaraba que la «electricidad tiende a convertirse en un artículo de primera necesidad para la industria moderna», lo cierto es que numerosos sectores industriales del país, y de la capital, comenzaban ya a utilizarla (Álvarez Isasi y Zorrozúa Arrietas, 2001).

41 Una de las excepciones fue el moderno taller de la Sociedad Española de Construcciones Metálicas donde toda la maquinaria se movía por electricidad. Ver «Talleres de Madrid de la Sociedad Española de Construcciones Metálicas». Revista Minera, Metalúrgica e Industrial, 1903, 204-206.

42 AGA, 24/10686.

43 En la Memoria de 1901 el Consejo le dice a los accionistas que «abriga grandes proyectos» como el ensanche de los «talleres dotándolos además de máquinas herramientas tan perfeccionadas, que sus rendimientos compensen con creces los gastos de su instalación». Reproducido en la Revista Ilustrada de Banca, Ferrocarriles, Industria y Seguros, Electricidad, Comercio, Obras Públicas, Metalurgia, Navegación, Agricultura, Aduanas, Minas y Tranvías, 1901, p. 322.

44 AHF, C/635/1-1; AHF, M/3/4.

45 AHF, C/635/1-14.

46 AHF, C/639/1-15.

47 AHF, C/635/1-12. 
en 5 metros de la cubierta del taller de calzar ruedas, pues «se encuentra en bastante mal estado»; construcción de un nuevo taller de fundición de cobre y de otro también nuevo de herramientas, liberando espacio al taller de tornos a fin de «poder colocar en él las nuevas máquinas herramientas que le son necesarias $\gg^{48}$ y prolongación de vía detrás del taller de carruajes para tener vías para el material ${ }^{49}$. Las obras de mayor empaque fueron la construcción de un edificio para el almacén de $\operatorname{maderas}^{50} \mathrm{y}$, sobre todo la ampliación del taller de montaje. A fin de «facilitar la reparación de las máquinas de 8 ruedas -le indicaba el Jefe de Material y Tracción al Ingeniero Jefe de Vía y Obras en oficio remitido en enero de 1899- se deben «alargar algunos fosos del taller de montaje» ${ }^{51}$; la modificación consiste -añade el Jefe de Material y Tracción- «en construir un muro exterior al actual a 4 metros de distancia [el existente se derriba, excepto los pilares situados entre los fosos] y con una longitud correspondiente a los 6 fosos que se deben alargar», colocando «de pilar a pilar vigas de hierro sobre los cuales se apoyarán los cuchillos intermedios». La modificación servirá más tarde -concluye- para las máquinas de bogie, aunque ello exigirá «cambiar la placa giratoria por otra de mayor diámetro, ensanchar el foso central de los cangrejos y reemplazar estos por otros de mayores dimensiones». De otra parte, para una «más amplia utilización de la grúa [28 toneladas de peso y de 7 de carga máxima, aparte del carbón y el agua] en las vías del taller se propone, en 1906, sustituir la vía de carriles sencillos por otra normal e instalar una placa giratoria frente a los talleres de montaje y tornos ${ }^{52}$. Se hicieron, además, otras obras menores como la reforma de las oficinas, archivo y vivienda del Jefe y Subjefe de los Talleres ${ }^{53}$ o la construcción de un foso en el taller de cerrajería para la instalación de la calefacción de vapor $^{54}$, y se perfeccionó el régimen de contabilidad ${ }^{55}$. No deja de sorprender que, cuando más se sentía la necesidad de arbitrar nuevos espacios, se trasladara el Taller de Puentes a las instalaciones del antiguo Almacén General ${ }^{56}$. Creado en 1873, la trayectoria de este taller fue similar a la de los Talleres Generales. Mal ubicado, su actividad fue al principio muy escasa. A finales de siglo sus instalaciones estaban desfasadas y el equipamiento tecnológico resultaba totalmente obsoleto. Se habían instalado cuando la red sólo era la mitad de la ahora existente y desde entonces apenas se habían realizado mejoras ni ampliaciones. Sin embargo, la extensión de la red, el deterioro del material fijo y el crecimiento espectacular del tráfico hicieron insostenible la situación. De ahí que se planteara trasladar las instalaciones a otro lugar; con ello se pretendía alcanzar un segundo objetivo no menos importante: liberar espacio para otros servicios de la estación no menos necesitados ${ }^{57}$. El nuevo local se ubicó -ya se dicho- en las instalaciones del antiguo Almacén General $^{58}$, lo que, si bien tenía la virtud de acercar el taller al Almacén General, como era el deseo de Nathan Süss, a la larga fue un error pues las posibilidades de expandirse serán nulas cuando se estaba procediendo al refuerzo y sustitución masiva de numerosos tramos metálicos y puentes giratorios, ampliación de estaciones y muelles, nuevos depósitos de

57 En 1904 el Director General, Nathan Süss, ordenó al Jefe de Vía y Obras que estudiara la viabilidad de trasladar el Taller de Puentes a los Antiguos Almacenes Generales pues, de ese modo, se conseguiría darle «el desarrollo necesario», teniendo además la ventaja de estar próximos a los Talleres Generales y a los Almacenes con los que tantas relaciones tienen (AHF, C/639/1).

$58 \mathrm{AHF}, \mathrm{C} / 652 / 2$.
} 
locomotoras y, en general, a la mejora de todo el material fijo. Por otro lado, cerró a los Talleres de Máquinas cualquier atisbo de expansión por este lado.

En resumen, pese a los esfuerzos realizados, los problemas de espacio lejos de resolverse se iban a complicar, como reconocerá ante el Consejo el Director General, E. Maristany, en $1913^{59}$. Las adquisiciones de material de toda clase realizadas por la empresa en los últimos años para «atender con el debido desahogo» las necesidades del tráfico creciente, exigen -dice E. Maristany- «la ampliación consiguiente de los Talleres Generales de Madrid, para la reparación del expresado material». Pero «la configuración del terreno y las especiales circunstancias que concurren en la estación de Madrid por su disposición, por la importancia de su tráfico, y por el relieve y precio de los terrenos inmediatos a la misma, dificultan enormemente el ensanche de los referidos Talleres, aconsejando el desdoblamiento de los mismos, en el sentido de trasladar a otro emplazamiento ciertas dependencias de aquellos, como son las destinadas a la reparación de coches y vagones y material fijo de la vía, que dejarían así disponible el espacio necesario para ampliar con la conveniente holgura, las actuales instalaciones dedicadas a la reparación de máquinas y ténders». La cita es larga, pero merecía la pena su reproducción pues sintetiza muy bien el problema. El lugar en el que piensa E. Maristany es Villaverde Bajo, junto a la estación, a ambos lados de la vía de Alicante. El nuevo lugar reúne unas condiciones óptimas: tiene la estación de Villaverde al lado, dista sólo siete kilómetros de Madrid, la configuración del terreno es la idónea para que las instalaciones puedan diseñarse con entera libertad, y los precios son asequibles. Aunque el Consejo aprobó un crédito de 90.000 pesetas para la compra de los terrenos (70 hectáreas, la operación, que sin duda era muy racional, no se realiza. Pero, ¿cómo eran, en realidad, esos Talleres que E. Maristany quería desdoblar geográficamente?

\subsection{Los Talleres Generales en 1913}

Bajo el epígrafe «Industrias de Madrid» en 1913 el BCOCIM publicó -ya se ha señalado- una sucinta descripción de los Talleres Generales en aquel momento. Comienza señalando su cometido principal, esto es, su «dedicación a la fabricación de piezas de repuesto necesarias para las pequeñas reparaciones en los Depósitos de locomotoras y Recorridos del material móvil y a la reparación general de todo lo que corresponde al Servicio de Material y Tracción». Efectúan para los otros servicios de la compañía (Movimiento, Vía y Obras y Minas) los trabajos que le demandan. También fabrican material nuevo como vagones, furgones y coches ${ }^{60}$. Las instalaciones y maquinaria le permiten construir locomotoras y ténders»; si no lo han hecho hasta el presente -subraya- «es por el mucho trabajo acumulado en las reparaciones generales, siendo muy frecuente «rehacer las locomotoras que entran a reparar». Enumera a continuación las diferentes secciones y subsecciones de que se componen, las de locomotoras y ténders: fraguas y fundición, calderería, ajuste y tornos y montaje; y las de vagones, coches y vagones: carpintería, cerrajería, pintura y guarnecido, amén de un comedor situado a la puerta de los talleres y un pequeño botiquín que permitía atender las lesiones pequeñas y practicar curas de urgencia. El conjunto de las instalaciones están relacionadas entre sí. «Disponen -añade- de una red completa de vía, con sus placas giratorias y carretones para la circulación de material entre los diversos edificios y en el interior de ellos, tanto para el material a reparar como para el transporte

59 AHF, S/162/221.

60 En los últimos 20 años se han construido 1.822 vagones, de ellos 712 de bordes bajos, 925 de bordes altos, 155 cerrados y 30 especiales para madera; además ha construido 60 coches de $3^{\mathrm{a}}$ y 6 coches-correo, teniendo en la actualidad en construcción 30 furgones para equipajes y 100 vagones de bordes altos de 15 toneladas de carga (BCOIPM, septiembre de 1913, pp. 1-8.). 
de las piezas al pie de la obra por medio de carros de diferentes tipos, apropiados todos a sus destinos». A renglón seguido especifica la tecnología de que están equipados: «para las maniobras de carga y descarga y levantado dispone de cinco grúas fijas ${ }^{61}$, cuatro grúas móviles, una grúa móvil de vapor de 7.000 kilogramos, dos puentes-grúa eléctricos de 10 toneladas con tres motores cada uno y otros dos de 30 toneladas con cuatro motores cada uno, siendo estos cuatro puentes de los más perfeccionados». Todo ello sin contar los «aparatos fijos y portátiles de potencias diversas repartidos en los talleres». Tiene, además: cinco motores eléctricos que reciben la corriente de la Gasificación Industrial ${ }^{62}$, y en caso de necesidad de la fábrica central de la estación; dos máquinas de vapor, alimentadas por tres calderas, aseguran una fuerza motriz total de 400 caballos; cuatro dinamos, movidas cada una por unas máquinas de vapor con fuerza de 200 caballos, garantizan el alumbrado. Dispone igualmente de 52 fraguas, 12 hornos diversos, tres cubilotes, cuatro ventiladores, cinco martillos pilones, un grupo hidráulico completo, compuesto de bomba, acumulador, prensa de 150 toneladas y remachadoras (una de ellas de 4,25 metros de luz), un grupo de aire comprimido, trescientas máquinas-herramientas de diversa clase completan los medios de producción, sin contar todas las máquinas portátiles y las herramientas menudas perfeccionadas. Y concluye: «cada año se dedican crecidas sumas para la adquisición de nuevas máquinas-herramientas de las más perfeccionadas». La idea de E. Maristany de desdoblar los Talleres Generales no surtió efecto, pero, en cambio, sí se realizó el traslado en 1924 a Villaverde del Taller de Puentes ${ }^{63}$, conocido desde entonces como taller Central, al que se dotó de una instalación y unos equipamientos modélicos y del que se sentirán muy orgullosos no sólo los ingenieros D. Mendizábal y A. Laffon sino la Dirección en pleno de la Compañía, aunque para ello hubo de esperarse a 1924, cuando las cuentas de la compañía, una vez superados las turbulencias de la Gran Guerra, presentan perspectivas lisonjeras. De hecho, fue el Taller Central y no los Talleres Generales lo que la Compañía mostró con todo lujo de de detalles a los cualificados asistentes al Congreso Internacional de Ferrocarriles de Madrid de 1930 (Martínez Vara y Cobos Arteaga, 2007). Su gran amplitud y lógica ordenación de trabajos y maniobras, amplios y modernos medios de transporte y removido y considerable número de las más punteras máquinas-herramienta, representaban el contrapunto de los Talleres Generales.

Estos, no obstante el hueco dejado por el traslado de aquel, seguirán adoleciendo de espacio donde asentar los nuevos equipos, un problema que se agravará a partir de los años veinte por dos razones: 1) la hiperactividad experimentada durante la Gran Guerra ocasionó un enorme desgaste del material, fijo y móvil, que no había sido suficientemente renovado hasta entonces; 2) el material rodante-locomotoras, coches vagones- no sólo aumentó (en 1930 la empresa disponía con relación a 1913 de un 43 por ciento más de locomotoras y de un 63,9 por ciento más de vagones) sino que era más complejo. Así lo hace saber E. Maristany al Administrador Delegado a finales de abril de 1923: «La construcción de nuevas locomotoras últimamente encargadas por esta Compañía o sea las ténders [Red Catalana], y

61 Ya en 1898 se manejaban grúas eléctricas de 30 toneladas (London and North Western) en Crew (ROP, $1898,45,1189$, p. 369).

62 Sociedad de Gasificación Industrial se creó el 7 de noviembre de 1902. Su objeto fue el de utilizar la hulla de mediana calidad para la producción del gas destinado á fuerza motriz. Muchos de sus accionistas estaban ligados a MZA. Suministró fluido electricidad a los Talleres Generales desde 1903, oscilando la potencia entre los 400 y 580 caballos de vapor, que dependía de la producción en cada momento del día y estación del año, dato importante para una correcta gestión (AHF, D/125/1).

63 Formaba parte de un plan quinquenal bastante ambicioso pues preveía hasta 1926 una renovación muy importante de las infraestructuras (obras destinadas a mejorar la seguridad de la explotación, atender al desarrollo del tráfico, dobles vías, etc.) y un aumento del material rodante (165 locomotoras, 295 coches, 353 furgones y 5697 vagones). (AHF, S/141/104). 
las Montaña [o equivalentes], destinadas a la Red Antigua, requieren que nuestros Talleres generales de Clot y Madrid estén en condiciones para que, una vez puestas en servicio estas máquinas, podamos efectuar en ellas las diversas reparaciones que estos motores vayan exigiendo para su buen entretenimiento». Urgía - continúa E. Maristany- «acometer en ellos las modificaciones que a tal objeto sean necesarias» ${ }^{64}$.

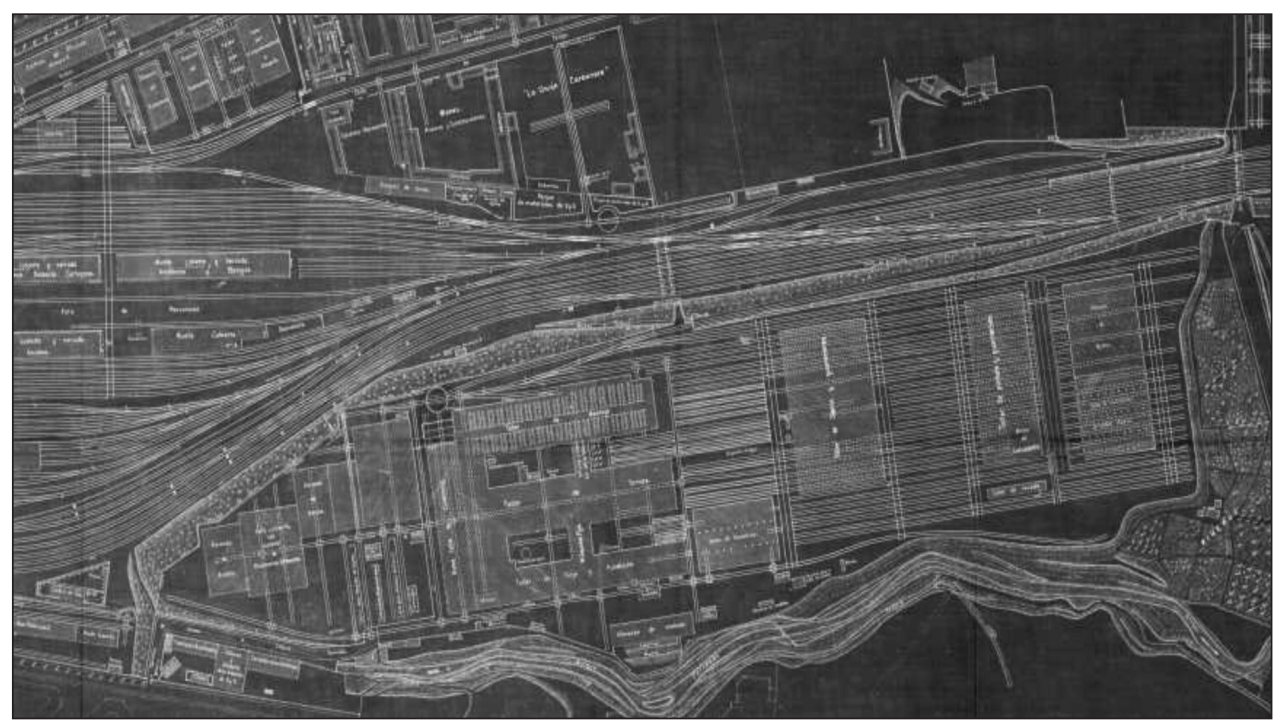

Figura 3. Mapa de los Talleres Generales en 1925.

Fuente: AHF, C/638/1.

A finales del mismo mes, en otra misiva remitida en este caso al Ingeniero Jefe de Material y Tracción, E. Maristany señala los trabajos que deberían realizarse en los Talleres Generales de Madrid: 1) «instalar un nuevo taller de montaje, separado de los talleres actuales por un patio ${ }^{65}$; 2) instalar un carro transbordador como prolongación del actual, pero con una longitud de 14 metros a fin de poder acceder a las más modernas locomotoras y a la nueva nave de montaje; 3) sustitución del actual puente giratorio por otro de 15 metros; 4) instalación de las grúas, tractores y demás maquinaria precisa». Las obras se harán una vez se hayan trasladado el Taller de Puentes y el almacén de Vía y Obras. Entre tanto procedía: «1) sustituir la actual placa giratoria por la de 15 metros indicada para que, girando con ella las nuevas locomotoras, puedan entrar en la vía central del actual taller de calderería; 2) prolongación del carro transbordador, ampliada su longitud hasta 14 metros, lo que permitirá la utilización de las otras vías emplazadas en el mismo taller ${ }^{66}$. La elongación de este carro hasta el nuevo taller de montaje y la construcción de este se realizarán en último lugar, es

64 AHF, S/164/255. A la Dirección General le preocupó enormemente la limitada capacidad de los Talleres Generales de Madrid y Barcelona Clot. Tanto que se llegó a dudar entre crear un nuevo talleres para las grandes reparaciones del material motor o recurrir, como de hecho se hará, a la industria particular (AHF, S/152/144).

65 Ver AGA, 24/19482, 12667 y 19441: Proyecto de obras complementarias del nuevo taller de Calderería y Montaje y patio cubierto.

66 Para la modificación del foso del carro transbordador y su instalación ver AHF, C/622/2-13 y 15. 
decir, cuando se haya trasladado el Central» ${ }^{67}$, que se ha de realizar lo antes posible pues sin el espacio que dejará libre «no se podrá atender las crecientes necesidades derivadas del tráfico ${ }^{68}$. Realizar las transformaciones necesarias para «alimentar con corriente continua todas las instalaciones» de los Talleres, lo que obligará a «aumentar las dimensiones de la caseta y de todos los elementos de la instalación ${ }^{69}$.

En su intento de renovar las infraestructuras y material rodante, MZA, como las demás ferroviarias, se verá favorecida por las aportaciones del Estado a través de la Caja Ferroviaria, un organismo creado en 1925 que se mantuvo hasta 1930 y fue eliminado por el ministro de Fomento L. Matos (Comín et alter, 1998: 301-308); los pedidos se deberían realizar a las industrias nacionales: ese era el objetivo subyacente, que no siempre se cumplió. Fue el momento culminante de la industria metalmecánica en España (Nadal el alter, 2003:180). Se aprobaron varios planes anuales de obras ferroviarias de mejora y de adjudicación de material. La Segunda República se encontrará con que la financiación pública a los ferrocarriles había sido pues suprimida. De los 197,4 millones que recibió MZA (fue una de las grandes beneficiarias), una parte, cuya cuantía exacta desconocemos, se destinó a la reforma, reemplazamiento y ampliación de los Talleres Generales ${ }^{70}$. No hubo un plan preconcebido, pero sí muchos los proyectos que no viene al caso comentar aquí ya que es tema que escapa de los objetivos de este trabajo. Citaremos, no obstante, algunos de ellos, dejando fuera otros como los referentes a los retoques y readaptaciones de los locales existentes así como la modificación y modernización de determinadas máquinas.

El más trascendente sin duda fue la reforma en dos etapas del sistema de suministro de energía eléctrica de los Talleres Generales (primera), facilitado por la Unión Eléctrica Madrileña, y la instalación da varios electromotores (segunda). A finales de octubre de 1926 E. Maristany remitía la memoria y el proyecto técnico y económico para la «instalación de una línea de alta tensión y estación de transformación» al Ingeniero Jefe de la $3^{a}$ División Técnica y Administrativa, que era quien debía informar al Consejo Superior de Ferrocarriles antes de su aprobación. El importe -225.000 pesetas- se debía al Plan de Obras aprobado en ese año, concretamente al capítulo «Instalaciones de alumbrado eléctrico en varias estaciones ${ }^{71}$. Pese al incremento de la demanda, las instalaciones del alumbrado apenas -se decía en la Memoria- habían variado desde de creación en 1890 . Su exagerado consumo de vapor, el desgaste de las dinamos, «la imperfección de los tipos de maquinaria»y, sobre todo, su escasa capacidad, que forzaba a una constante sobrecarga, «justifican el cambio». La fuerza motriz, ya de por sí escasa cuando se instaló en 1903, es -añade el Proyecto- «completamente insuficiente, agravándose el problema día a día por el aumento incesante para los nuevos motores» ${ }^{72}$. De ahí la urgencia de una reforma total.

67 AHF, S/164/255; AHF, C/622/2-15 y 17.

68 AHF, Actas del Comité de Dirección, sesión del 11 de diciembre de 1923.

69 AHF, W/52/5.

70 Sí sabemos que para la mejora de todos los talleres y Depósitos se destinó un total de 8,2 millones de pesetas (AGA, 24/499). «En cuanto a los perfeccionamientos en nuestra maquinaria útil de alto rendimiento, se han llevado a cabo -son palabras de la excelente publicación de la Compañía en 1932 Actuación de la Compañía durante los últimos veinte años (1913-1931)- importantes adquisiciones [como] tornos de ruedas, fresas, tornos revólveres y paralelos, máquinas radiales de taladrar, tornos verticales, aparatos de soldadura eléctrica y oxiacetilénicas, limadoras, martillos pilón, máquinas de roscar, etc., con cuyas máquinas se ha mejorado el rendimiento de los talleres. Más hubiera hecho la Compañía en este terreno, pero desde que la Caja ferroviaria limitó, hace dos o tres años, los recursos para mejora, nada o casi nada ha sido posible realizar, dándose el caso de tener construida en los Talleres Generales de Madrid una nueva nave de montaje para las modernas locomotoras que no puede utilizarse por falta de grúas-puentes, como consecuencia de no habérsenos podido facilitar hasta ahora por la Caja ferroviaria los fondos necesarios para la adquisición de aquellos elementos de trabajo» (MZA, 1932:197-198).

71 AGA, 24/19570; AHF, C/312/1-4.

72 AGA, 24/10686. 
Para la ejecución del Proyecto se propone un «sistema mixto de concurso limitado y gestión directa». El edificio para la estación transformadora dentro del recito de los Talleres, entre el almacén de modelos y el arroyo Carcabón ${ }^{73}$, lo deberá construir el Taller Central de Vía y Obras mientras que a la Unión Eléctrica Madrileña, responsable del suministro, compete el pequeño trozo de línea de alta tensión desde su caseta a la estación de transformación; su capacidad se eleva a 1450 kilovatios, con posibilidades de incremento. La adquisición de transformadores, aparatos de maniobra y seguridad y la instalación de la estación de transformación propiamente dicha se propone a concurso limitado entre las diversas casas de reconocida solvencia técnica. El mencionado Ingeniero Jefe de la $3^{a}$ División Técnica y Administrativa refrenda en todos sus términos lo expuesto en el Proyecto, que es aprobado sin alteración ${ }^{74}$. Para la adquisición de los electromotores se propone también concurso limitado entre casas de reconocida solvencia. Los trabajos los realizarán los agentes del propio Servicio Eléctrico, perfectamente capacitados a tal fin, sin necesidad de paralizar la actividad ordinaria ${ }^{75}$.

Uno de los primeros objetivos consistió en pertrechar el nuevo taller de fundición de hierros, ya terminado, al que se proveería de la «maquinaria y herramental» pertinente sin escatimar gastos ${ }^{76}$. «Son necesarios dos cubilotes con una producción horaria de 6.000 kilos de hierro fundido»; rezaba el pliego de condiciones a los potenciales licitadores. Estos debían especificar producción, potencia y presión de aire, contando que la «corriente eléctrica es continua a 220/240 voltios». Hacen falta, asimismo, «tres máquinas de moldear comprendiendo cada grupo dos máquinas de moldear y una de ensamblar», «tres carros porta trócolas», un molino triturador de continuo, capaz de producir 5 ó 6 metros cúbicos de arena por hora y varios tipos de mezcladores. Además, las casas constructoras podrán hacer ofertas separadamente para cada uno de los útiles siguientes: dos cucharas, una de 6000 kilos de capacidad y la otra de 2000 kilos; un horno metálico con guarnición refractaria; una máquina de hacer machos cilíndricos de 10 a $57 \mathrm{~mm}$ de diámetro; una estufa para secar los machos; dos máquinas desbarbadoras, con dos piedras de esmeril cada una, accionadas por su correspondiente motor; y una báscula múltiple de 8 balanzas para pesar las diferentes cargas de los cubilotes. Por último, sirven el local dos puentes-grúas, uno de 15 y otro de 5 toneladas, con motor eléctrico. Anexos al taller de Fundición, inmediato a él, se colocaría (1929) su complemento obligado: el parque de materiales para el almacenamiento del carbón (cubierto), lingote y chatarra (descubierto), y el almacén de arena y transportador automático de la misma, que se situaría provisionalmente en el antiguo secadero, junto al almacén de modelos, con una capacidad para almacenar 100 metros cúbicos. Para la construcción del parque la Compañía propone, y la $3^{\text {a }}$ División acepta, el sistema de gestión directa; el coste de las obras, que sobrepasa con creces las cien mil pesetas, es abonado por la Caja Ferroviaria con cargo al plan de mejora de $1929^{77}$.

Coincidiendo con el anterior, el Jefe de la División de Talleres envía un escrito al Jefe de Material y Tracción sugiriéndole la conveniencia de modificar y ampliar el taller de reparación de muelles, cuyas máquinas están almacenadas sin que se puedan instalar. Un año después, el 28 de mayo de 1928 MZA solicita a la Dirección General de Ferrocarriles y Tranvías le autorice -la respuesta es positiva- adquirir e instalar las máquinas necesarias para un nuevo taller de la reparación de muelles, entre las que se encuentran: una prensa hidráulica de 40 toneladas para embridar muelles, otra de 60 para desembridarlos, una pun-

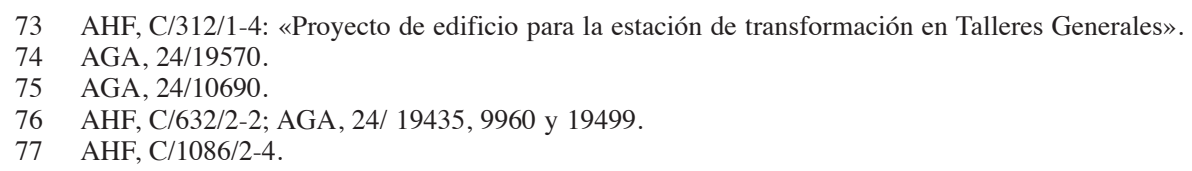


zonadora especial de 5 herramientas, una máquina de envolver extremos de hojas maestras, un horno para el tratamiento térmico, una máquina de curvar hojas de muelles, además de otro instrumental complementario ${ }^{78}$.

Asimismo, la Dirección de la Compañía solicita de la Jefatura de la $3^{\circ}$ División Técnica y Administrativa de Ferrocarriles autorización para la construcción de «un nuevo taller de calderería y montaje y patio cubierto», adyacente al actual, que ya se había proyectado construir en 1923 para hacer frente a la entrega por parte de la Maquinista Terrestre y Marítima de varias locomotoras Montaña ${ }^{79}$. Pero la construcción del nuevo taller requería la liberación del espacio del derribo del Taller de Puentes que aún no se había trasladado a Villaverde. Entretanto, conviene se sustituya -propone E. Maristany al Ingeniero Jefe de Material y Tracción- la placa giratoria por una de 15 metros para que las locomotoras puedan girar y entran en la vía central del actual taller central de calderería; realizar la prolongación del carro transbordador, ampliada su longitud hasta 14 metros, lo que permitiría la utilización de la de otras vías emplazadas en el mismo taller. La prolongación de este carro hasta el nuevo taller de montaje y la construcción de éste se realizará en último lugar, cuando se haya trasladado el taller de Puentes, lo que sucederá en 1924. La Memoria que acompañaba al nuevo proyecto mencionado, presentado en 1927 a la Jefatura de la $3^{\circ}$ División Técnica y Administrativa de Ferrocarriles, incidía, como justificación, en la necesidad creada por la «insuficiencia de capacidad» del taller existente para hacer frente al aumento de la demanda de reparaciones ${ }^{80}$. Una razón que el Ingeniero Jefe de la $3^{\text {a }}$ División Técnica y Administrativa aceptaba como muy suficiente. Demolido el Taller de Puentes, el nuevo taller correría paralelo al actual, separado de él por un espacio de catorce metros donde se ubicará el patio cubierto. Se le dotaría de dos puentes grúas para el traslado dentro de él. Para su ejecución y como en otras ocasiones, E. Maristany propone -y el Comité Ejecutivo de la $3^{\text {a }}$ División acepta- un sistema mixto, esto es, gestión directa a través del taller Central para las obras de emplazamiento, estructuras metálicas y modificación e instalación de vías; y subasta en el caso de la construcción del taller de calderería y fosos. El coste total superaba las ochocientas mil pesetas a abonar por la Caja Ferroviaria ${ }^{81}$. A finales de abril de 1928 el proyecto fue aprobado. Ese mismo mes el Ingeniero Jefe de Material y Tracción comunica al Ingeniero Jefe de Vía y Obras la necesidad de comenzar las obras cuanto antes y se proceda a la subasta, que gana Valentín Vllhonrat ${ }^{82}$. En plena construcción, en 1929, E. Maristany remite al Comité Ejecutivo un proyecto adicional que le es aceptado e incluye algunas rectificaciones del primero. Básicamente de lo que se trataba era de dejar el taller actual exclusivamente para calderería y destinar el nuevo sólo a montaje cuyos operarios se librarían del gran ruido producido por el remachado del taller de calderería ${ }^{83}$. Era algo de lo que ya se había percatado el director del Taller, L. Benoist, como lo demuestra su crítica al proyecto remitido al Jefe de la División de Talleres Generales ${ }^{84}$. En diciembre

78 AGA, 24/19499.

79 AHF, S/164/255; AHF, C/622/2-15-18.

80 AHF, C/1092/1.

81 AGA, 24/19482.

82 AGA, 24/19482; AHF, C/1092-1. La Compañía presenta un escrito a la Jefatura de Ferrocarriles, solicitando la adquisición de cinco puentes giratorios articulados de 23 metros de diámetro, un compresor y máquinas herramientas con destino a las diferentes subsecciones de los Talleres Generales: una fresadora universal, un torno vertical, una prensa hidráulica de 40 toneladas para embridar, otras para desbridar, una punzonadora, una máquina de envolver hojas, un horno para el tratamiento térmico, dos puentes grúas de 50 toneladas, tres juegos de gatos, y una máquina de curvar hojas. La respuesta del Comité Ejecutivo de la mencionada Jefatura es positiva (AGA, 24/19499).

83 AGA, 24/19482; la liquidación de la obras en AGA 24/12667.

84 L. Benoist fundaba su crítica en su larga experiencia y su conocimiento de los talleres franceses (AHF, $\mathrm{C} / 1092 / 1)$. 
de 1929 la $3^{\text {a }}$ División Técnica y Administrativa aprueba el proyecto adicional, cuyo coste se eleva a 180 mil pesetas ${ }^{85}$. La obra culmina con la ejecución en 1932 del proyecto de obras complementarias menores (despachos para los contramaestres, instalación de aire comprimido, chimenea de uralita para el patio cubierto, etc.) de dicho taller ${ }^{86}$.

Las cosas tampoco marchaban todo lo bien que cabía esperar en el taller de carruajes. Así se lo hacía saber el 19 de diciembre de 1929 el Jefe de Talleres al Ingeniero Jefe de Material y Tracción: «el constante aumento de ejes montados de máquinas y carruajes que se reciben en estos Talleres para reparar, nos ha creado dificultades muy serias que es urgente resolver (....) La prensa hidráulica, para calar y descalar, actualmente en servicio es insuficiente, y como usted sabe, proyectamos utilizar, con la presión del acumulador de Calderería, otra de las dos prensas viejas que estaban inutilizadas. Para la buena marcha de las dos prensas y para establecer una organización del trabajo en serie, necesitamos introducir en nuestro taller de acuñación, algunas modificaciones» como añadir vías a las existentes, colocar una plataforma para girar vagones, ampliar la sala de máquinas y modificar el taller de sierras.

\section{Epílogo}

Los Talleres Generales de MZA, dependientes del servicio de Material Tracción, fueron, como en todas las grandes ferroviarias, el lugar donde se realizaban las reparaciones importantes, modificaciones y reconstrucciones de material rodante. Se trató en el ámbito regional, y hasta bien entrado el siglo XX, de la industria más relevante de Madrid. Daban empleo a centenares de empleados, a muchos de los cuales se les presuponía una buena cualificación, pues no pocas de las reparaciones que debían de realizar eran tan complejas que a menudo acababan convirtiéndose en verdaderas reconstrucciones u obras realmente nuevas. Comenzaron a funcionar a finales de la década de los cincuenta en Madrid, reemplazando a los muy modestos que en aquel momento había en Aranjuez (locomotoras) y en Madrid (remolcado), pertenecientes a la antigua Compañía del Ferrocarril Madrid-Aranjuez (1851). Se construyeron sobre terrenos situados a la derecha de la estación de Atocha, cabecera de la doble red (Levante y Zaragoza), entre las vías al norte, el arroyo de las yeserías al sur y la acequia de la Abadía al este. El relieve accidentado en el que se ubicaron no sólo dificultó su comunicación sino que también limitó su expansión. Se realizaron grandes esfuerzos para ampliar las instalaciones y hacer frente a las necesidades que los nuevos equipos y material rodante así como el propio crecimiento del negocio requerían, pero los problemas de espacio continuaron incluso después del traslado del Taller de Material Fijo a Villaverde Bajo, una localidad del sur de Madrid, situada a siete kilómetros.

\section{Bibliografía citada}

ÁlVAREZ ISASI, R. y ZORROZÚA ARRIETA, M.A. (2001): «La evolución histórica de la red eléctrica en Alta Tensión», en F.J. AYALA-CARCEDO, Historia de la Tecnología en España. Barcelona. Valantena, pp. 267-278.

AUBANELL JUBANY, A. M. (2004): «Business Strategies in Electricity Firms in Comparison: Hidrola and Unión Eléctrica Madrileña, 1907-1935, en 8th annual conference of the European Business History Association (EBHA). Barcelona, Universitat Pompeu Fabra.

BOLETIN DE LA CAMARA OFICIAL DE LA INDUSTRIA DE MADRID (1913): «Industrias de Madrid», pp. 1-8.

85 AHF, C/1092/1: Memoria, planos, pliego de condiciones y presupuesto.

86 AGA, 24/19441y 24/661. 
BOUGHEY, D. (1999): «The Internationalisation of Locomotive Building by Britain's Railway Companies during the Nineteenth Century», en Business and Economic History, ${ }^{\circ}$ 28-1, pp. 57-68.

CARON, F. (2003): «Â propos de la rationalisation du travail dans les ateliers des compagnies des chemins de fer en France, 1880-1936», en Revue d'Histoire des Chemins de Fer, nº. 28-29. pp. 190-206.

CAYON, F. y MUÑOZ RUBIO, M. (2005): «iQue fabriquen ellos! La fabricación de máquinas vapor en España. ¿Una ocasión perdida para la Industria?», En PASCUAL, P. y FERNÁNDEZ, P. (Eds.): Del metal al motor. Innovación y atraso en la industria metal-mecánica española. Bilbao, Fundación BBVA, pp. 287-340.

CHEVANDIER, C. (1993): Cheminots en usine. Les ouvriers des Ateliers d'Oullins au temps de la vapeur. Lyon, Presses Universitaires de Lyon.

COMIN, F. et Alter (1998): 150 Años de Historia de los Ferrocarriles en España. Madrid. Anaya.

DRUMMOND, D. (1995): Crewe; railway town, company and people, 1840-1914. Scolar Press, Aldershot.

GRAVES, C. (1981): «Applying Scientific Management Principles to Railroad Repair Shops. The Santa Fe Experience, 1904-1918», en Business and Economic History, n 10, pp. 124-136.

GUAJARDO, G. (2009): «Between the Workshop and the State: Training Human Capital in Railroad Companies in Mexico and Chile, 1850-1930», Working Paper, junio de 2009, National Autonomous University of Mexico.

LALANA, J. L. (2003): «Los talleres ferroviarios de Valladolid: del siglo XIX al XXI», en III Congreso de Historia Ferroviaria. Siglo y medio de ferrocarril en Asturias, Gijón.

LALANA, J. L. (2005): «Establecimientos de grandes reparaciones de locomotoras de vapor: los talleres de Valladolid», en Revista de Historia Ferroviaria, no 4, pp. 45-82.

LALANA, J. L. (2007): «Los talleres generales en el ferrocarril europeo. Un patrimonio olvidado», en Revista de Transportes, Servicios y Telecomunicaciones [TST], n ${ }^{\circ} .12, \mathrm{pp} .70-93$.

LALANA, J. L. y SANTOS GANGES, L. (2006): «Exploring the Modernizing Process of Railway Workshops», en II IRHA Conference: Railway Modernization, Lisbon.

LANDES, D. S. (1979): Progreso Tecnológico y Revolución Industria. Madrid. Tecnos.

LARKIN, E. (1992): An illustrated History of British Railways Workshops. Locomotive, Carriage and Wagon Building and Maintenance, from 1825 to the Present Day .Somerset, Oxford Publishing Co. Apankford.

LOPEZ GARCÍA, M. (1986): MZA: Historia de sus estaciones. Madrid. Colegio de Ingenieros de Caminos, Canales y Puertos.

MARTÍNEZ VARA, T. y COBOS ARTEAGA, F. (2007): «Taller central de vía y obras», en Transportes, Servicios y Telecomunicaciones [TST], $\mathrm{n}^{\circ}$ 12, pp. 94-120.

MENDIZABAL, D. (1919): «Congreso Nacional de Ingeniería. Unificación de tipos», en Revista de Obras Públicas, $\mathrm{n}^{\circ}$ 2307, pp. 605-607.

MZA (1862): Colección de las Instrucciones, Circulares y Disposiciones relativas al servicio de los Ferrocarriles I. Madrid. Imprenta y Estereotipia de M. de Rivadeneira.

MZA (1908): Reglamento provisional para la contabilidad de los Servicios de la Red Antigua. Madrid. Establecimiento Sucesores de Rivadeneyra.

MZA (1934): Situación del personal en la Compañía M.Z.A. (1913-1933). Madrid. Sucesores de Ribadeneyra.

NADAL, J. et alter (2003): «Las industrias en la Segunda Revolución Industrial», en Atlas de la industrialización de España, 1750-2000, Madrid, Fundación BBVA-Crítica, pp. 180-203.

PERDONNET, A. (1860): Traité élémentaire des chemins de fer. París. Langlois et Leclerq.

RAHOLA, S. (1913-1923): Tratado de Ferrocarriles. Madrid. Rivadeneyra, 6 vols.

RAHOLA, S. (1930): La Tracción por vapor en los Ferrocarriles. Madrid. Librería Internacional de Romo.

RUIZ, V. (1895): Lecciones de Caminos de Hierro. Madrid. Establecimiento Tipográfico Ricardo Álvarez.

SANTOS Y GANGES, L. (2003): «Una gran instalación productiva en la ciudad: la estación de la Compañía del Norte y sus talleres», en CARASA, P. (coord.): La ciudad y el tren. Talleres ferroviarios en Valladolid 1856-1936. Valladolid, Ayuntamiento de Valladolid, pp. 113-141.

SHARLIN, H. (1981): «Aplicaciones de la electricidad», en KRANZBERG, M. y PURSWELL, C. W. Jr. (eds.): Tecnología y Cultura. Barcelona, Gustavo Gili, pp. 627-643. 
TEDDE DE LORCA, Pedro (1978): «Las compañías ferroviarias en España», en ARTOLA, M. (dir.) Los ferrocarriles en España, 1844-1943. Madrid, Banco de España, Vol. 2. pp. 13-355.

VALLÉE, S. (1958): Guía de Contramaestre. Barcelona. Francisco Casanovas Editor.

VALLESPIN Y SARABIA, M. (1875): Lecciones provisionales sobre ferrocarriles. Madrid. Imprenta del Memorial de Ingenieros.

VAN HEESVELDE, P. (2009): «A city whitin the city? Mechelen and the Arsenal Central Workshop of the State Railways, 1836-1914». en V Congreso de Historia Ferroviaria, Palma de Mallorca. WAIS, F. (1949): Compendio de Explotación Técnica de Ferrocarriles. Barcelona-Madrid. Labor. 